\title{
openheart Analysis of mortality trends due to cardiovascular diseases in Panama, 2001-2014
}

\author{
María Carrión Donderis, ${ }^{1}$ Ilais Moreno Velásquez, ${ }^{1}$ Franz Castro, ${ }^{1}$ Julio Zúñiga, \\ Beatriz Gómez, ${ }^{1}$ Jorge Motta ${ }^{1,2}$
}

To cite: Carrión Donderis M, Moreno Velásquez I, Castro F, et al. Analysis of mortality trends due to cardiovascular diseases in Panama, 2001-2014. Open Heart 2016;3:e000510. doi:10.1136/openhrt-2016000510

Received 28 July 2016 Revised 20 October 2016 Accepted 8 November 2016

\section{ABSTRACT}

Objective: Cardiovascular diseases (CVDs) are still the leading cause of death worldwide despite the recent decline in mortality rates attributable to CVD in Western Europe and the Americas. The aim of this study is to investigate mortality trends due to ischaemic heart disease (IHD) and stroke in Panama from 2001 to 2014, as well as the mortality differences by sex and age groups.

Methods: Data were obtained from the National Mortality Register. The International Classification of Diseases 10th revision codes (ICD-10) I20-I25 and 160-169 were used for IHD and stroke, respectively. Age-adjusted mortality rates were calculated using the world population of the WHO as standard. Trends were analysed using Joinpoint Regression Program and annual percentage changes (APC) were estimated. Results: From 2010, the IHD mortality trend began to decline in the whole population of Panama (APC $-4.7 \%, p<0.05$ ). From 2001 to 2014, a decline in the trend for IHD mortality was observed (APC $-1.7 \%$, $\mathrm{p}<0.05)$ in women, but not in men. Stroke mortality showed a significant annual decline during the study period (APC $-3.8 \%, p<0.05$ ) and it was more pronounced in women (APC $-4.5 \%, p<0.05$ ) than in men (APC -3.3\%, $\mathrm{p}<0.05)$.

Conclusions: In Panama, the mortality rates from IHD and stroke have declined in recent years. Better access to healthcare, improved treatment of acute IHD and stroke, low tobacco consumption and better control of hypertension probably account for a significant part of this mortality reduction.

\section{CrossMark}

\section{${ }^{1}$ Gorgas Memorial Institute for Health Studies, Panama City, Panama \\ ${ }^{2}$ National Secretariat for Science and Technology, Panama City, Panama}

Correspondence to Dr María Carrión Donderis; mteresacarriond@gmail.com

\section{INTRODUCTION}

Despite recent declines in mortality rates attributable to cardiovascular disease (CVD) in Western Europe and North America, CVD is still a leading cause of death worldwide. ${ }^{1}$ In Latin America, CVD remains the most important cause of death, and four out of five deaths are caused by ischaemic heart disease (IHD) or stroke. ${ }^{2}$

Panama is an upper middle-income country where non-communicable diseases, and within these, CVD dominate the

\section{KEY QUESTIONS}

What is already known about this subject?

- Cardiovascular disease (CVD) is a global public health concern. As with other countries in the region, CVD is the leading cause of death in Panama. Recent studies performed in developed and developing countries, including Latin America, have reported a decline in mortality trends due to CVD.

What does this study add?

- This is the first national study for Panama that has evaluated recent general and sex-specific mortality trends due to ischaemic heart disease (IHD) and stroke. The results show a sustained decrease in the trend of stroke mortality from 2001 to 2014, for both sexes and in all age groups. For IHD, a decrease in the mortality trend was observed starting from 2010 and this was most marked in women. In contrast to these findings, we observed a rise, albeit nonsignificant, in mortality trends due to IHD and stroke among young adults.

How might this impact on clinical practice?

- Improved measurement of the incidence of CVD and of the prevalence of cardiovascular risk factors could result in public health strategies aimed at sustaining the observed decreasing trends in mortality and avoiding a future reversal. A turnaround of the observed trends could occur due to a rise of risk factors like obesity and diabetes mellitus. This study underscores the need to implement a national registry to record the incidence and prevalence of CVD risk factors in Panama.

mortality profile. ${ }^{3}$ In the last decade, Panama has experienced socioeconomic changes evidenced by a sustained economic growth, a modest poverty reduction and an expansion of its social services network. ${ }^{4}$ In 2008, Panama was the first country in the region to implement an absolute ban on advertising, promoting and sponsoring tobacco products. Moreover, a large tax increase on tobacco 
products was implemented by law. ${ }^{5}$ The most recent surveys of tobacco consumption in Panama reported a prevalence of $6.1 \%$, one of the lowest in the world. ${ }^{6}$

IHD and stroke mortality partly reflect the patterns and impact of risk factors in the national population. However, the variations of mortality caused by CVD throughout time have not been previously studied with robust statistical tools. Thus, the aim of this study is to describe the mortality trend of IHD and stroke in Panama from 2001 to 2014 using National Mortality Register (NMR) data. As differences in CVD risk factors and disease incidence among sexes have been reported, ${ }^{7}$ a secondary aim is to explore the mortality trends by age and sex.

\section{MATERIALS AND METHODS}

We conducted a retrospective registry-based study of mortality trends due to IHD and stroke in the Republic of Panama, for the years 2001-2014.

Data were obtained from the NMR of the Department of Vital Statistics of the National Institute of Statistics and Census. This department is the government agency responsible for the compilation and codification of deaths occurring in Panama. The process of compiling and coding deaths is performed by trained personnel. A study of Panama's vital statistics data conducted between 1990 and 1999 concluded that the data were of medium quality. ${ }^{8}$ Nevertheless, a recent study on the performance of civil registration and vital statistics systems in 148 countries from 1980 to 2012 reported that the data of Panama were of high quality. ${ }^{9}$

No substantial changes in the International Classification of Diseases 10th revision codes (ICD-10) were performed during the time frame for this analysis. The cause of death was recorded using ICD-10 codes I20-I25 and I60-I69 for IHD and stroke, respectively. During the study period, a total of 21581 deaths due to IHD were recorded, $58.9 \% \quad(n=12711)$ were men and $41.1 \%(\mathrm{n}=8870)$ were women. Regarding stroke, a total of 19653 deaths were recorded, of which 53.2\% $(n=10460)$ were men and $46.8 \%(n=9193)$ were women. Of the total number of deaths analysed, $98.3 \%$ were certified by a doctor.

Specific mortality rates were calculated as the number of deaths per 100000 , using the mortality data and the estimates and projections of the total population of Panama to July 1st for each year, according to sex and age, based on the last census conducted in 2010. These specific mortality rates were standardised for 5-year age groups using the direct method and the world standard population of the WHO as reference. We categorised the age groups starting at $\geq 35$ years of age, according to 10 -year age groups, grouping in the oldest category those $\geq 75$ years of age.

For the trend analysis, we used the regression program Joinpoint V.4.2.0.2. This statistical software helps to find the best-fit line through several years of data, determining whether a multisegmented line is a significantly better fit than a straight line. The points where line segments are joined are called 'joinpoints', and each joinpoint denotes a statistically significant change in trend. The program also performs permutation tests to determine the number of 'joinpoints' necessary for statistical significance. To describe and test the significance of each period, an average annual percentage change (APC) of the trend was estimated with $95 \%$ CIs and $\mathrm{p}$ values. IBM SPSS Statistics V.19 was used to manage databases and GraphPad Prism V.6.01 to generate the graphs and perform statistical analysis.

As this study analysed anonymous secondary data on mortality, no ethics approval was required.

\section{RESULTS}

\section{Ischaemic heart disease}

From 2001 to 2010, the age-adjusted mortality rate from IHD showed a horizontal trend (APC $-0.03 \%, \mathrm{p}=0.96$ ) (figure 1). From 2010 onwards, the IHD mortality rate showed a significant downward trend (APC $-4.7 \%$, $\mathrm{p}<0.05)$. During the same period $(2010-2014)$, the mortality due to IHD stratified by sex showed a significant downward trend only in women (APC $-1.7 \%, \mathrm{p}<0.05$ ) (table 1). This decrease was driven by the mortality trends seen in older women. In men, no significant change in the mortality rate from IHD was noted during the study period.

The analysis of the age-specific mortality rates by sex for the years 2001 and 2014 revealed that the rates increased with age for both sexes. When comparing mortality rates from 2001 with those from 2014, we observed that the mortality rate in women below 45 years increased from 1.5 per 100000 in 2001 to 6.2 per 100000 in 2014. Similarly, in men below 45 years, the mortality rate increased from 6.4 per 100000 in 2001 to 10.1 per 100000 in 2014 (figure 2).

We found no significant difference in the median age of death from IHD among men and women who died in 2001 compared with 2014. In 2014, the median (IQR)

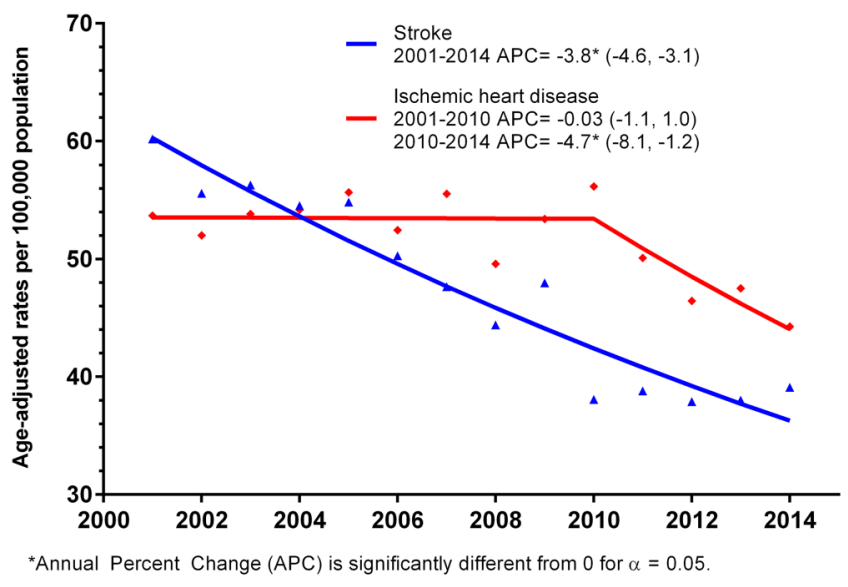

Figure 1 Mortality trends from ischaemic heart disease and stroke in Panama, from 2001 to 2014. Annual percentage change (APC), $95 \% \mathrm{Cl}$. 
Table 1 Age-specific mortality trends from ischaemic heart disease by sex in Panama, from 2001 to 2014

\begin{tabular}{|c|c|c|c|c|}
\hline \multicolumn{5}{|c|}{ Ischaemic heart disease } \\
\hline \multirow[b]{2}{*}{ Age group } & \multicolumn{2}{|l|}{ Trend 1} & \multicolumn{2}{|l|}{ Trend 2} \\
\hline & Period & APC $(95 \% \mathrm{Cl})$ & Period & APC $(95 \% \mathrm{Cl})$ \\
\hline \multicolumn{5}{|l|}{ Men } \\
\hline $35-44$ & 2001-2014 & $1.3(-3.4$ to 6.3$)$ & & \\
\hline $45-54$ & 2001-2014 & $-0.9(-3.3$ to 1.6$)$ & & \\
\hline $55-64$ & 2001-2014 & $-0.5(-1.9$ to 1.0$)$ & & \\
\hline $65-74$ & 2001-2014 & $-0.1(-1.0$ to 0.7$)$ & & \\
\hline $75+$ & 2001-2014 & $-1.0(-2.1$ to 0.1$)$ & & \\
\hline Total & $2001-2014$ & $-0.8(-1.6$ to 0.1$)$ & & \\
\hline \multicolumn{5}{|l|}{ Women } \\
\hline $35-44$ & 2001-2014 & $5.4(-0.03$ to 11.2$)$ & & \\
\hline $45-54$ & 2001-2014 & $1.5(-2.9$ to 6.2$)$ & & \\
\hline $55-64$ & 2001-2007 & $3.5(-2.0$ to 9.4$)$ & 2007-2014 & $-6.5^{\star}(-10.4$ to -2.3$)$ \\
\hline $65-74$ & 2001-2014 & $-2.0^{*}(-3.6$ to -0.3$)$ & & \\
\hline $75+$ & 2001-2014 & $-1.5^{\star}(-2.3$ to -0.7$)$ & & \\
\hline Total & 2001-2014 & $-1.7^{\star}(-2.6$ to -0.8$)$ & & \\
\hline
\end{tabular}

${ }^{*} \mathrm{p}<0.05$.

APC, annual percentage change.

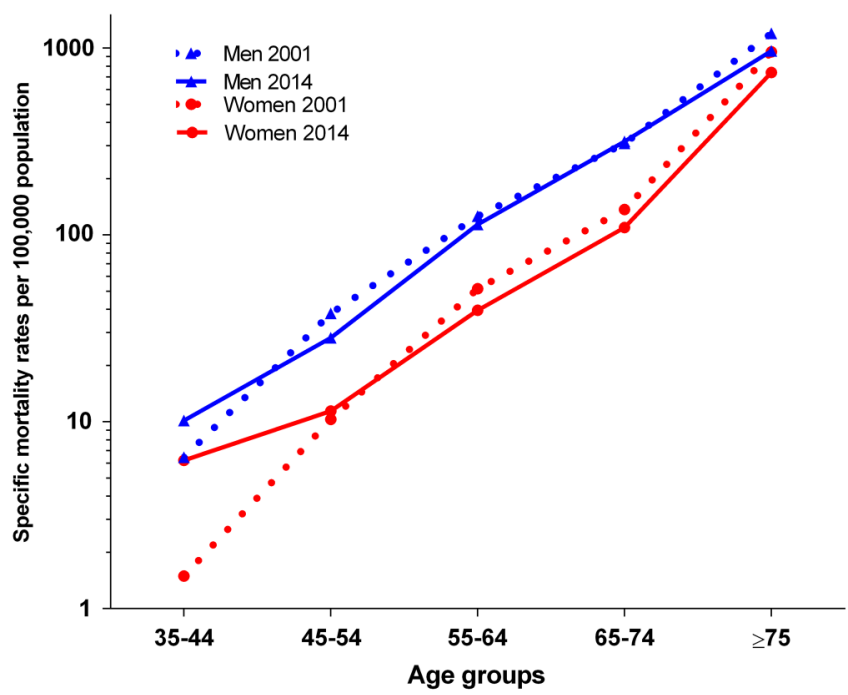

Figure 2 Specific mortality rates from ischaemic heart disease by sex and age group in Panama, 2001-2014. On the $\mathrm{Y}$-axis, specific mortality rates are plotted by age and sex on a logarithmic scale, and on the $X$-axis, the age groups at 10-year intervals.

age of death from IHD for men was 75 (65-84) years and for women was $82(72-90)$ years, respectively $(p<0.01)$.

\section{Stroke}

Stroke mortality showed a decreasing trend throughout the 14 years of the study period (APC $-3.8 \%, \mathrm{p}<0.05$ ) (figure 1). The age-adjusted mortality rates by sex also showed a decrease in the mortality trends for both sexes, and this was more pronounced in women (APC $-4.5 \%, \mathrm{p}<0.05)$ as compared with men (APC $-3.3 \%$, $\mathrm{p}<0.05$ ) (table 2).

In women, the trend in age-specific mortality rates from stroke from 2001 to 2014 showed a significant decrease in all age groups, except for those below 45 years of age (table 2). For men, the trend in agespecific mortality rates for stroke in the group aged 3544 years showed a decline between the years 2001 and 2010 (APC $-15.0 \%, \mathrm{p}<0.05$ ), while in the group aged 65-74 years, there was a downward trend between the years 2005 and 2010 (APC $-9.1 \%, \mathrm{p}<0.05$ ) (table 2).

Women aged 35-44 years had a higher mortality rate from stroke in 2014 (6.2 per 100000$)$ compared with 2001 (4.0 per 100000 ). In all of the other female and male age groups, the mortality rate from stroke was lower in 2014 than in 2001 (figure 3).

The median (IQR) age of death due to stroke increased from $82(73-88)$ to $83(73-90)$ years in women during the study period $(\mathrm{p}<0.05)$, whereas in men, it increased from 77.5 (68-85) to 79 (68-87) years, albeit not significant. In 2014, the median age of death from stroke was 4 years higher in women than in men $(p<0.001)$.

\section{DISCUSSION}

This is the first national study performed in Panama evaluating recent general age and sex-specific mortality trends due to IHD and stroke using robust statistical tools. The study revealed a sustained decrease in trends for stroke mortality from 2001 to 2014, in both sexes and in all age groups. For IHD, a decrease in mortality trends was observed from 2010 in both sexes and in all age groups.

Studies performed recently in other countries have also shown a decline in the trends of mortality from CVD..$^{11}$ In Western Europe, total CVD mortality has markedly declined with decreases observed also for IHD and stroke. ${ }^{12}{ }^{13}$ North American countries have had higher declines of CVD death rates when compared with countries in Latin America and the non-Latin Caribbean. ${ }^{14}$

In most countries of the Americas, the age-adjusted CVD death rates have dropped from the year 2000 for 
Table 2 Age-specific mortality trends from stroke by sex in Panama, from 2001 to 2014

\begin{tabular}{|c|c|c|c|c|c|c|}
\hline \multicolumn{7}{|l|}{ Stroke } \\
\hline \multirow[b]{2}{*}{ Age group } & \multicolumn{2}{|l|}{ Trend 1} & \multicolumn{2}{|l|}{ Trend 2} & \multicolumn{2}{|l|}{ Trend 3} \\
\hline & Period & APC (95\% Cl) & Period & APC $(95 \% \mathrm{Cl})$ & Period & APC $(95 \% \mathrm{Cl})$ \\
\hline \multicolumn{7}{|l|}{ Men } \\
\hline $35-44$ & 2001-2010 & $-15.0^{*}(-23.5$ to -5.7$)$ & 2010-2014 & $42.9(-0.5$ to 105.4$)$ & & \\
\hline $45-54$ & 2001-2014 & $-0.8(-2.5$ to 0.9$)$ & & & & \\
\hline $55-64$ & 2001-2014 & $-2.2^{*}(-3.3$ to -1.0$)$ & & & & \\
\hline $65-74$ & 2001-2005 & $0.2(-7.7$ to 8.8$)$ & 2005-2010 & $-9.1^{*}(-16.3$ to -1.2$)$ & 2010-2014 & $4.0(-4.2$ to 13.0$)$ \\
\hline $75+$ & 2001-2014 & $-3.2^{*}(-4.0$ to -2.4$)$ & & & & \\
\hline Total & 2001-2014 & $-3.3^{*}(-4.0$ to -2.5$)$ & & & & \\
\hline \multicolumn{7}{|l|}{ Women } \\
\hline $35-44$ & 2001-2014 & $1.1(-2.6$ to 4.9$)$ & & & & \\
\hline $45-54$ & 2001-2014 & $-4.6^{*}(-8.2$ to -0.9$)$ & & & & \\
\hline $55-64$ & 2001-2014 & $-2.8(-5.5$ to 0.1$)$ & & & & \\
\hline $65-74$ & 2001-2014 & $-4.5^{*}(-6.1$ to -2.9$)$ & & & & \\
\hline $75+$ & 2001-2014 & $-4.3^{*}(-5.3$ to -3.3$)$ & & & & \\
\hline Total & 2001-2014 & $-4.5^{*}(-5.4$ to -3.5$)$ & & & & \\
\hline
\end{tabular}

${ }^{*} \mathrm{p}<0.05$.

APC, annual percentage change.

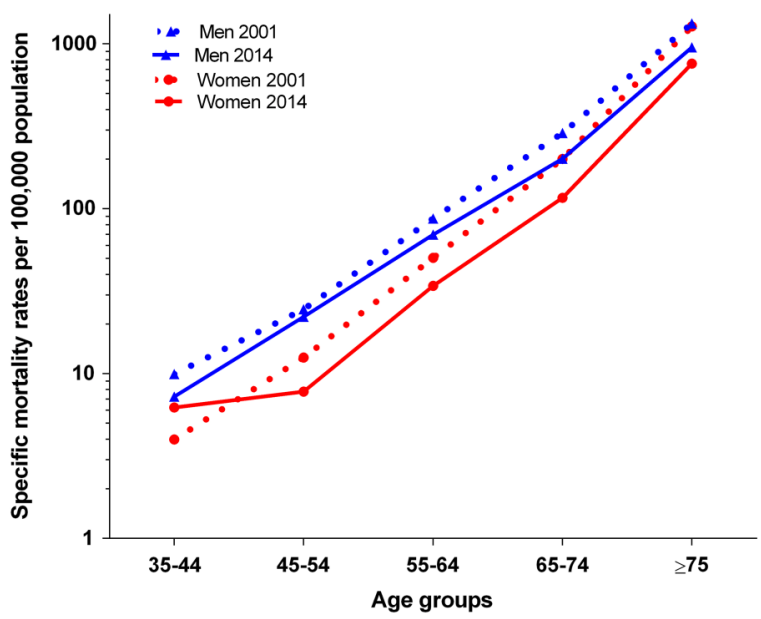

Figure 3 Specific mortality rates from stroke by sex and age group in Panama, 2001-2014. On the Y-axis, specific mortality rates are plotted by age and sex on a logarithmic scale, and on the $\mathrm{X}$-axis, the age groups at 10 -year intervals.

both men and women, and the death rates for CVD have been shown to be higher among upper middle and lower middle-income countries. ${ }^{11}$ That study also showed no significant changes in the trends of CVD mortality in Panama from 2000 to 2009. This result could, in part, be due to the fact that this study included mortality induced by all diseases of the circulatory system and only carried its analysis up to the year 2009 . In our study, we observed that mortality due to IHD began to decrease from the year 2010 onwards.

\section{Decrease in mortality from IHD and stroke}

Several reasons might have contributed to the decrease in the mortality trends from stroke and IHD that have been noted in Panama.
High blood pressure (HBP) is the most important modifiable risk factor for the development of any type of stroke. ${ }^{15}$ HBP is also an important risk factor for the development of IHD. A Panamanian study published in 2014 reported that $63 \%$ of strokes were ischaemic, and that the most common risk factor associated with stroke was HBP $(73 \%) .{ }^{16}$ Prospective clinical trials have shown that a decline in blood pressure, even if modest, could result in a reduction of the risk of developing stroke. ${ }^{15}$

A cross-sectional study on the prevalence of risk factors for CVD (Prevalencia de factores de riesgo asociados a enfermedad cardiovascular (PREFREC)), performed in two provinces of Panama where $60 \%$ of the country's population resides, reported that $72.8 \%$ of the study population had blood pressure measured by a health professional in the previous 12 months. In addition, $67 \%$ of those found to have HBP or a history of HBP were receiving hypertensive treatment. ${ }^{17}$ These levels of detection and treatment of HBP, in part due to primary healthcare programmes, have probably impacted the incidence of stroke and IHD and might somehow be related to the decrease in the mortality of these two pathologies.

Tobacco consumption has been proven to be a risk factor for CVD because of its relationship with atherosclerosis, endothelial damage, platelet activation, increase of blood viscosity and also, in the short term, it increases the rigidity of the arterial wall which can lead to the rupture of atherosclerotic plaques. ${ }^{15}$ It has been shown in the elderly that the biological effects of tobacco on cardiovascular mortality are more related to current use compared with the risk accumulated by a history of consumption (former smokers). ${ }^{18}$ The observed decrease in the mortality trend from IHD since 2010 may be partly due to a decrease in tobacco consumption related to the aforementioned 
antismoking measures. In fact, the implementation of these laws was associated with a reduction of tobacco consumption and a reduction in the occurrence of acute myocardial infarction. ${ }^{19}$

Intravenous thrombolytic therapy was introduced in Panama in 2013 as a treatment for ischaemic stroke. ${ }^{16} \mathrm{In}$ the context of mortality reduction due to stroke, this benefit probably occurred in a minority of patients who were evaluated and treated in tertiary care hospitals. We believe that the greatest impact in reducing stroke and IHD-related mortality has been better access to healthcare, improved training of healthcare delivery personnel, better preventive measures of poststroke complications, reduction of tobacco consumption and improved HBP control in the general population.

\section{Divergence in trends}

A global study that evaluated mortality from stroke relative to IHD mortality using 2004 data reported a small difference in mortality $(0-5 \%)$ between stroke and IHD in Panama. ${ }^{20}$ Similarly, our age-adjusted mortality rates from IHD and stroke were 54.2 and 54.5 per 100000 , respectively, for that year. Subsequently, the mortality between both diseases began to diverge in ensuing years. While stroke mortality maintained a decreasing trend throughout the whole study period, it was not until 2010 that IHD mortality began to descend.

IHD and stroke have atherosclerosis as a common pathophysiological mechanism and also share certain modifiable and non-modifiable risk factors. While HBP, alcohol abuse and advanced age are stronger predictors for stroke, dyslipidaemia, diabetes mellitus (DM), obesity and smoking appear to be more associated with IHD. ${ }^{1521}$

Some people may have had risk factors for both diseases. It is likely that those at risk of suffering a stroke could have acquired a survivorship advantage after first suffering an IHD event, which might have induced behavioural changes associated with a reduction of stroke-related risk factors. It is also possible that those who were at risk of suffering a stroke, died at an earlier age from IHD, thus reducing the number of people that could have died later from stroke. ${ }^{22}$

Nevertheless, in order to better explain the decreasing trends in mortality, the relation between incidence and mortality from IHD and stroke needs to be studied. It is possible that these decreasing trends in mortality are the result of a reduction in lethality and not necessarily a decline in the incidence of these diseases. ${ }^{23}$ Furthermore, there is a need to determine the relative contribution of primary prevention programmes, which reduce the incidence, and/or secondary prevention programmes and improved hospital care, which decrease the lethality of stroke and IHD.

The fact that we found a decrease in mortality rates without an increase in median age of death from these diseases suggests that it is necessary to promote healthier lifestyles and to improve access and quality of health services. It was not possible for us to analyse in parallel the trends of incidence and mortality, as we do not have a national registry of CVD. Additionally, we did not evaluate the knowledge, attitudes and practices of the Panamanian population regarding the recognition of IHD and stroke symptoms, which might have produced earlier access to a health facility to receive proper treatment.

\section{Difference between sexes}

Our study has shown lower mortality rates from stroke and IHD in women than in men. These differences might be due to physiological characteristics intrinsic to sex, behaviour concerning health habits, or a combination of both.

Women reported a statistically significant higher frequency of preventive health evaluations than men in a national survey of health and quality of life held in Panama in $2007 .{ }^{24}$ The PREFREC study also showed a statistically significant difference between men and women when assessing whether they had their blood pressure measured. ${ }^{17}$ Of those already diagnosed with HBP, a higher percentage of women reported receiving antihypertensive treatment, compared with men, although this difference was not statistically significant. ${ }^{17}$ In addition, women had a lower prevalence of smoking $(3.1 \%)$ than men $(9.7 \%) .{ }^{6}$ Finally, other potential explanations for the observed mortality differences might be related to socioeconomic disparities that affect the prevalence of several CVD risk factors between sexes. ${ }^{25}$

\section{Mortality in young adults}

One of the issues that emerges from our study is the apparent elevation of IHD and stroke in men aged 3544 years and of IHD for women in that same age group. Although the APC CIs are wide, other studies have reported increasing trends in stroke mortality in adults aged 20-54 years. ${ }^{26} 27$ The observed increase of mortality among the young adults could be related to the use of recreational drugs, to the increased prevalence of cardiovascular risk factors such as obesity and DM, or to a reduced usage of healthcare services. ${ }^{26}$ Some studies have reported a flattening trend in IHD mortality for this age group; however, the evidence that supports this finding has been considered insufficient. ${ }^{27}$

In the young Panamanian population, there has been an increase in the smoking prevalence reported by global youth tobacco surveys performed in 2008 and $2012 .^{28}$ This increase could possibly be influencing the elevation of mortality from stroke and IHD noted in this younger age groups. Moreover, a Panamanian study reported that the prevalence of obesity has been increasing in both sexes, particularly in women. ${ }^{29}$ The prevalence of obesity in the PREFREC study was $30.9 \%$ in women and $18.3 \%$ in men. Additionally, only $19.9 \%$ of the surveyed population reported doing physical activity. ${ }^{30}$ All of this suggest that the control of obesity and DM as risks factors for CVD are areas that need to be 
strengthened if we are to continue to see a sustained decrease in mortality due to these two diseases.

The increase in risk factors among young people is a clear warning signal that in the future we may see a reversal in the mortality trend from CVD. ${ }^{27}$ It is imperative that we continue to monitor the evolution of these risk factors that could trigger public health problems, which in turn become a burden to the healthcare system and society. ${ }^{26}$

\section{Limitations}

Several limitations need to be acknowledged. Owing to quality of data issues, we chose not to use mortality data prior to 2001 and thus, the number of years evaluated was restricted. ${ }^{8}{ }^{9}$ Under-reporting of deaths still persists predominantly in the indigenous regions but the impact of this on our mortality estimates is minor as this occurs in small groups that live in remote areas. Owing to a lack of data on the incidence of CVD, we were not able to ascertain whether the observed decreases in the mortality trends were associated with a decrease in the incidence or a decrease in lethality. Finally, we could not adjust for potential confounding factors such as socioeconomic status or comorbidities that might have an impact on CVD mortality.

\section{CONCLUSION}

In Panama, the age-adjusted mortality rates from stroke and IHD have declined in recent years. Better access to healthcare, improved treatment of acute IHD and stroke, low tobacco consumption and better control of HBP, as outcomes of health policies instituted in the last decade, probably account for a significant part of this mortality reduction.

We need to measure, follow and better understand the incidence of these diseases and the perception among the population of the cardiovascular risk factors in order to continuously adjust public health strategies so that, in the future, the observed reductions of mortality from stroke and IHD are not eclipsed by the rise of other risk factors like obesity and DM. Finally, this study highlights the need to implement a national registry to record incident GVD in Panama.

Contributors MCD curated, analysed and interpreted the data, did the research and wrote the draft of the work. IMV interpreted the data, did the research and critically revised the draft for important intellectual content. FC and $J Z$ interpreted the data, did the research and wrote the draft of the work. $\mathrm{BG}$ and JM designed and supervised the work and critically revised the draft for important intellectual content. Final approval of the version to be published was given by MCD, IMV, FC, JZ, BG and JM. All the authors agree to be accountable for all aspects of the work in ensuring that questions related to the accuracy or integrity of any part of the work are appropriately investigated and resolved.

Funding This research received no specific grant from any funding agency in the public, commercial or not-for-profit sectors.

Competing interests None declared.

Provenance and peer review Not commissioned; externally peer reviewed.
Data sharing statement No additional data are available.

Open Access This is an Open Access article distributed in accordance with the Creative Commons Attribution Non Commercial (CC BY-NC 4.0) license, which permits others to distribute, remix, adapt, build upon this work noncommercially, and license their derivative works on different terms, provided the original work is properly cited and the use is non-commercial. See: http:// creativecommons.org/licenses/by-nc/4.0/

\section{REFERENCES}

1. Go AS, Mozaffarian D, Roger VL, et al. Executive summary: heart disease and stroke statistics--2014 update: a report from the American Heart Association. Circulation 2014;129:399-410.

2. World Health Organization. Cardiovascular Diseases (CVDs). Fact sheet. Website of the World Health Organization, 2016.

3. The World Bank. Cause of death, by non-communicable diseases (\% of total) Panama. 2016.

4. Moreno LA. La década de América Latina y el Caribe, una oportunidad real. Segunda edición ed. Banco Interamericano de Desarrollo, 2011.

5. Herrera Ballesteros V. Análisis de la demanda de tabaco en Panamá y el control del efecto de asequibilidad con medidas fiscales y control del contrabando: Implicaciones para Política Fiscal 2000-2011. Instituto Conmemorativo Gorgas de Estudios de la Salud, 2013

6. Roa Rodríguez R. Encuesta Mundial de Tabaco en Adultos: Panamá 2013. Instituto Conmemorativo Gorgas de Estudios de la Salud, 2015:227.

7. Han $\mathrm{SH}$, Bae JH, Holmes DR Jr, et al. Sex differences in atheroma burden and endothelial function in patients with early coronary atherosclerosis. Eur Heart $J$ 2008;29:1359-69.

8. Mathers CD, Fat DM, Inoue M, et al. Counting the dead and what they died from: an assessment of the global status of cause of death data. Bull World Health Organ 2005;83:171-7.

9. Mikkelsen L, Phillips DE, AbouZahr C, et al. A global assessment of civil registration and vital statistics systems: monitoring data quality and progress. Lancet 2015;386:1395-406.

10. Ordunez P, Prieto-Lara E, Pinheiro Gawryszewski V, et al. Premature Mortality from Cardiovascular Disease in the AmericasWill the Goal of a Decline of " $25 \%$ by 2025 " be Met? PLOS ONE 2015;10:e0141685.

11. de Fatima Marinho de Souza M, Gawryszewski VP, Orduñez P, et al. Cardiovascular disease mortality in the Americas: current trends and disparities. Heart 2012;98:1207-12.

12. Bhatnagar $\mathrm{P}$, Wickramasinghe $\mathrm{K}$, Wilkins $\mathrm{E}$, et al. Trends in the epidemiology of cardiovascular disease in the UK. Heart 2016;102:1945-52.

13. Rücker V, Keil U, Fitzgerald AP, et al. Predicting 10-year risk of fatal cardiovascular disease in Germany: an update based on the score-Deutschland risk charts. PLOS ONE 2016;11:e0162188.

14. Gawryszewski VP, Souza Mde F. Mortality due to cardiovascular diseases in the Americas by region, 2000-2009. Sao Paulo Med J 2014;132:105-10.

15. Soler EP, Ruiz VC. Epidemiology and risk factors of cerebral ischemia and ischemic heart diseases: similarities and differences. Curr Cardiol Rev 2010;6:138-49.

16. Gracia F, Benzadon A, Gonzalez-Castellon M and, et al The impact of cerebrovascular disease in Panama. Int J Stroke 2014;9(Suppl A100):28-30.

17. Mc Donald A, Motta J, Roa R, et al. Prevalencia de factores de riesgo asociados a enfermedad cardiovascular (PREFREC) en la población adulta de 18 años y más. Provincias de Panamá y Colón: Instituto Conmemorativo Gorgas de Estudio de la Salud, 2010.

18. LaCroix AZ, Lang J, Scherr P, et al. Smoking and mortality among older Men and Women in three communities. $N$ Engl J Med 1991;324:1619-25.

19. Jan C, Lee M, Roa R, et al. The association of tobacco control policies and the risk of acute myocardial infarction using hospital admissions data. PLOS ONE 2014;9:e88784.

20. Kim AS, Johnston SC. Global variation in the relative burden of stroke and ischemic heart disease. Circ 2011;124:314-23.

21. Simons LA, Simons J, Friedlander $Y$, et al. A comparison of risk factors for coronary heart disease and ischaemic stroke: the Dubbo study of Australian elderly. Heart Lung Circ 2009;18:330-3.

22. Haberman S, Capildeo R, Rose FC. Diverging trends in cerebrovascular disease and ischaemic heart disease mortality. Stroke 1982;13:582-9.

23. Cayuela A, Cayuela L, Escudero-Martinez I, et al. Analysis of cerebrovascular mortality trends in Spain from 1980 to 2011. Neurologia 2016;31:370-8. 
24. Moreno A, Roa R, Mc Donald A, et al. Encuesta nacional de salud y calidad de vida, 2007. Instituto Conmemorativo Gorgas de Estudios de la Salud, 2007.

25. Malki N, Koupil I, Eloranta S, et al. Temporal trends in incidence of myocardial infarction and ischemic stroke by socioeconomic position in Sweden 1987-2010. PLoS ONE 2014;9:e105279.

26. Kissela BM, Khoury JC, Alwell K, et al. Age at stroke: tempora trends in stroke incidence in a large, biracial population. Neurology 2012;79:1781-7.

27. O'Flaherty M, Ford E, Allender S, et al. Coronary heart disease trends in England and Wales from 1984 to 2004: concealed levelling of mortality rates among young adults. Heart (British Cardiac Society) 2008;94:178-81.

28. Roa Rodríguez R. Global Youth Tobacco Survey. Panama. Instituto Conmemorativo Gorgas de Estudios de la Salud, 2012.

29. Sasson M, Lee M, Jan C, et al. Prevalence and associated factors of obesity among Panamanian adults. 1982-2010. PLOS ONE 2014;9:e91689.

30. Mc Donald A, Bradshaw RA, Fontes F, et al. Prevalence of obesity in Panama: some risk factors and associated diseases. BMC Public Health 2015;15:1075. 